\title{
Coelhos: tecnologia humana e tecnologia material
}

Lucas Ferraço Nassif*

RESUMO: Este ensaio discute os conceitos de diagrama e de dispositivo a partir do debate entre Peter Eisenman e Rem Koolhaas, tentando pensá-los nas relações entre arquitetura e arquitetura conceitual.

PALAVRAS-CHAVE: diagrama, dispositivo, arquitetura conceitual.

ABSTRACT: This essay discusses the concepts of diagram and dispositive, trying to think them in the relationship between architecture and conceptual architecture. KEYWORDS: diagram, dispositive, conceptual architecture.

\footnotetext{
*Lucas Ferraço Nassif é doutorando no programa de Literatura, Cultura e Contemporaneidade da PUC-Rio. Realizou mestrado em Arquitetura pela PUC-Rio sendo orientado por Otávio Leonídio em sua dissertação, "Formas de vida e de morte". Seu curta "Reinforced Concrete" é parte do trabalho "Labour in a single shot" de Harun Farocki e de Antje Ehmann e seu longa "Being Boring" foi exibido na Semana dos Realizadores, Rio de Janeiro, em 2015 e na Mostra de Cinema de Tiradentes, em 2016.
} 
Como está fora do nosso controle, o urbano está prestes a se tornar o vetor máximo da imaginação. Redefinido, o urbanismo não será mais, ou mais que tudo, uma profissão, mas um modo de pensar, uma ideologia: aceitar o que existe. Nós estávamos fazendo castelos de areia. Agora nadamos no mar que os varreu para longe.

Para sobreviver, o urbanismo terá que imaginar um novo Novo. Liberado de suas tarefas atávicas, o urbanismo redefinido como modo de operar sobre o inevitável irá atacar a arquitetura, invadir suas trincheiras, afastá-la de seus bastiões, minar suas certezas, explodir seus limites, ridicularizar suas preocupações com matéria e substância, destruir suas tradições, desmascarar seus profissionais.

(KOOLHAAS, 1995, p. 969-967)

O debate neste ensaio concentra-se nos conceitos de "diagrama" e de "dispositivo". Ele se passa no diálogo entre Peter Eisenman e Rem Koolhaas. O objeto de estudo que permite perguntar "o que são os conceitos de 'diagrama' e de 'dispositivo' é o 'Muro de Berlim'. Essa não foi uma escolha ao acaso: o muro é estudado por Koolhaas num artigo que faz parte de seu livro "S, M, X, XL" (1995); o estudo do muro provoca discussões e viabiliza a investigação que leva ao pensamento acerca desses conceitos.

Os entendimentos sobre "diagrama" e "dispositivo" precisam ser claros - ao redor deles e sobre eles há muita dúvida e muito interesse. A pergunta que me orienta é: "na 'arquitetura conceitual' de que fala Peter Eisenman, como poderia apresentar os conceitos de 'diagrama' e de 'dispositivo'; o que eles dizem sobre a 'arquitetura conceitual'?".

Este texto não é uma "Field trip" (KOOLHAAS, 1995, p. 212) da maneira como se pensa "uma viagem de campo"; ele é um ato de imaginação, de questionamentos que ocorrem pela minha leitura de outras leituras - não de minha experiência física junto aos momentos em que o muro estava de pé ou em que o muro estava em queda. Eu nasci nos fragmentos do muro - meus encontros físicos com ele foram com seus fragmentos expostos enquanto "cultura", quase turismo -, numa suposta "nova ordem" das coisas, dos poderes, do mundo. Todos os encontros foram pagos em Euro, moeda que destaca a arquitetura em suas cédulas; o muro não está aparente nelas, no entanto.

A idade da queda do 'Muro de Berlim' é a minha idade. O muro caiu alguns dias antes de meu nascimento: eu nasci dia dezoito, ele caiu dia nove. Somos escorpianos. O que isso diz? Diz que Escorpião é o signo do zodíaco que nos rege. A imagem das forças escondida ou não em nossas ações interpretadas. 
O que está em jogo é a possibilidade de interpretação de ações numa imagem do zodíaco.

Mas por que trazer o Escorpião para escrever acerca da queda do 'Muro de Berlim'? Uso uma alegoria como estratégia biográfica para me aproximar enquanto leitor do objeto que procuro debater - objeto que não é somente o muro, mas a queda do muro - e que faz da relação leitor-objeto também um texto que pode ser debatido. Apontar o Escorpião é como indicar um esquema interno para o objeto que é a queda do muro.

Este texto se passa entre a queda do muro e a imagem do Escorpião que digo que rege a queda. Ele parte de uma pergunta que pousa sobre as ações do e no muro.

A pergunta é: como o muro se torna frágil e cai?

Essa pergunta se dobra e se desdobra, fazendo vincos, em outras perguntas: há imagem dessa fragilidade que provoca a queda? A fragilidade é do muro ou está no muro? Etc.

A imagem do Escorpião é chamada para pensar as ações - ações que são ligadas à imagem do Escorpião pela ação de interpretação. Há ânsia pela interpretação.

Existem, portanto, três pontos a serem considerados como principais nestes levantamentos iniciais: a fragilidade, a queda, a interpretação. Um estado, um efeito, uma ação que passa entre o estado e o efeito.

Para pensar a imagem da queda é preciso pensar a imagem da não-queda.

O que faz o muro ficar de pé?

A não-queda do muro me permite contestar o Escorpião como o signo do zodíaco correspondente à queda. Digo isso, pois não é possível determinar apenas um signo para o período em que o muro não-caiu. E se o muro não-caiu por vários signos - pois os signos do zodíaco são administrados num calendário -, não seria um equívoco concentrar a queda em apenas um signo, em apenas um momento? De pé ou em queda, resistente ou frágil, as ações do e no muro exigem outra interpretação que não se faz na impressão de um instante e que constrange o meu uso da imagem do Escorpião. Eu não posso, diante do texto que é a queda do 'Muro de Berlim', valer-me apenas dessa figura - dessa alegoria - para justificar a ação que é a sua queda (ou de apenas outra figura para justificar sua permanência).

Mas o momento do nascimento, que é decisivo, é apenas um instante. Isso evoca outra particularidade na esfera do semelhante. Sua percepção, em todos os casos, dá-se num relampejar. Ela perpassa veloz, e, embora talvez possa ser recuperada, não pode ser fixada, ao contrário de 
outras percepções. Ela se oferece ao olhar de modo tão efêmero e transitório como uma constelação de astros. A percepção das semelhanças, portanto, parece estar vinculada a uma dimensão temporal. A conjunção de dois astros, que só pode ser vista num momento específico, é observada por um terceiro protagonista, o astrólogo. Apesar de toda a precisão dos seus instrumentos de observação, o astrônomo não consegue igual resultado. (BENJAMIN, 2010, p. 110)

É Walter Benjamin quem me incita a utilizar o zodíaco ao trazer a imagem do Escorpião. Entretanto, é também ele quem me faz repensar nessa primeira maneira de ler a queda do Muro de Berlim. A imagem das forças que rege a ação é fissurada, pois existem outros textos que interferem na minha interpretação inicial que via o Escorpião como aquilo a ser descoberto, revelado, e que estaria por detrás da ação da queda do muro. Esses textos me fazem pensar outras possibilidades de diálogo com meu objeto.

A queda do Muro de Berlim é um texto que pode ser lido; mas não sem percalços, uma vez que minha leitura sofre interferência de outros textos que me acompanham nessa ação de ler a queda do Muro de Berlim como um texto. Um de meus interlocutores é Rem Koolhaas. Há também Peter Eisenman, Walter Benjamin, Gilles Deleuze e Michel Foucault.

A imagem do Escorpião - que antes parecia nítida por detrás das ações do muro - é borrada, indefinida, implodida, intrigada, retirada. O Escorpião é apagado com borracha deste texto e um "vazio" se dá no lugar da imagem que justifica a queda do muro. Usar a borracha, no entanto, deixa marcas: restam alguns fragmentos de interpretação, críticas, especulações, possibilidades, oportunidades para outras leituras. Posso escrever sobre o apagado: palimpsesto (EISENMAN, 2007, p.93), ou mesmo escrever sem notar, sem perceber o que está apagado - podendo até mesmo seguir os traços que não são muito visíveis.

A intriga é a falta de imagem regente da ação do e no muro. É dessa falta de imagem regente que a investigação se vale; não para buscar uma imagem que reja a ação, mas para que na busca sejam levantadas questões e para que debates sejam provocados. A inquietação da falta da imagem é motivo para outra ação que está além da descrição da queda, para o questionamento teórico do e no muro. Uma escrita e uma leitura que entende o muro não como um elemento da arquitetura opaco e funcional - e tampouco como um elemento transparente possuidor de um único significado a ser revelado.

O muro - sua queda e sua permanência - são geridos por algo. O muro, e as ações dele e nele, se passam numa guerra fria que provoca a administração de uma construção, de uma permanência e de um tombo. 
Quem fortalece e quem fragiliza?

O muro é um projeto de quem? Um projeto de que? Um projeto para o que?

O que gere a queda e a permanência do muro é também o que gere o nós. Ele não apenas divide Berlim - a cidade, as cidades de Berlim. Ele aponta para a divisão que atua sobre o nós, é instrumento da tensão entre poderes, em relação. O muro poderia ser dispositivo, efeito de um diagrama de forças.

O diagrama não é mais o arquivo, auditivo ou visual, é o mapa, a cartografia, co-extensiva a todo o campo social. É uma máquina abstrata. Definindo-se por meio de funções e matérias informes, ele ignora toda distinção de forma entre um conteúdo e uma expressão, entre uma formação discursiva e uma formação não discursiva. É uma máquina quase muda e cega, embora seja ela que faça ver e falar. (DELEUZE, 2013, p. 44)

Falar do diagrama é falar de uma "tecnologia humana" (DELEUZE, 2013, p. 49) que é marcante na ação da técnica, do instrumento, do dispositivo. Diagrama e dispositivo são conceitos que se relacionam: um sofre do efeito do outro, do efeito que é o outro, um é causado pelo outro.

O diagrama seleciona o seu ou os seus dispositivos. O dispositivo permite a discussão acerca do diagrama que o seleciona.

Quando Rem Koolhaas faz sua viagem de campo para Berlim, com o objetivo de conhecer o muro, ele produz um texto. Nele, há uma pequena parte inicial que acredito ser um prólogo e que se organiza de maneira a destoar do resto do texto. O que chamo de prólogo é uma cena em que Koolhaas descreve o que estava em jogo e o que acontecia para ele, no Architectural Association (AA) durante seus anos de formação para se tornar um arquiteto. O AA é uma famosa escola de arquitetura em Londres; essa pequena parte destoante com a qual Koolhaas abre o seu texto me faz pensar que o encontro entre ele e o muro de Berlim o põe a escrever sobre um incômodo.

O incômodo de Rem Koolhaas é a arquitetura. A escola de arquitetura, o discurso, a disciplina.

A escola em alvoroço sobre a mística tomar o lugar do enredo. Teoria: existe apenas uma quantidade limitada de conhecimento no mundo que deve, portanto, não ser espalhada homogeneamente ou democraticamente - ela ficaria muito escassa. (1995, p. 215)

A cidade é um espaço dos dispositivos, de "tecnologia material" (DELEUZE, 2013, p. 49) causada por uma relação de forças e que geram a contenção de seus habitantes, suas organizações 
e desorganizações. Pensar a cidade, o urbano, é uma oportunidade para realizar um trabalho acerca do conceito de dispositivo - e, do dispositivo, investigar o conceito de diagrama.

O diagrama não é gerado em si mesmo ou de si mesmo. Ele abre uma repressão que limita uma capacidade generativa e transformativa, uma repressão que é constituída tanto na anterioridade da arquitetura quanto no sujeito. O diagrama não contém em si um processo de superação da repressão. Todavia, o diagrama permite que 'umx' 'autorx' supere e acesse a história do discurso enquanto, simultaneamente, supera seu ou sua resistência física a realizar esse ato. (EISENMAN, 2007, p. 94)

Koolhaas vai para Berlim, a cidade dividida de Berlim, para dela escrever sobre seu incômodo. O que incomoda Koolhaas é o saber da arquitetura que esconde atender relações de força, ao poder. É na cidade que ele observa a exposição desse atendimento - assim como a desobediência a esse atendimento. Na prática cotidiana da cidade que insiste em sair do controle, na falta de autoria e de assinatura de diversos de seus elementos, no controle de seus habitantes e no descontrole que eventualmente emerge há a possibilidade de outra abordagem da arquitetura.

O que torna essa experiência desconcertante e (para os arquitetos) humilhante é a persistência desafiadora da cidade e seu aparente vigor, não obstante a falência coletiva de todas as agências que operam sobre ela ou tentam influenciá-la - criativamente, logisticamente, politicamente. Os profissionais da cidade são como jogadores de xadrez que perdem para computadores. Um piloto automático perverso constantemente passa a perna em todas as tentativas de apreender a cidade, esgota as ambições de defini-la, ridiculariza as afirmações mais apaixonadas quanto à sua falência atual e sua impossibilidade futura, a conduz implacavelmente além no seu voo à frente. Cada desastre profetizado é de algum modo absorvido pela infinita anulação do urbano. (KOOLHAAS, 1995, p. 961)

Estão em debate a ética, a apreensão de um objeto, a leitura de um objeto, a escrita, os limites do saber e a vontade de gerar outras maneiras de se pensar-agir (n)a arquitetura - ou de destruí-la para, quem sabe, vislumbrar alguma liberdade nessa tentativa.

Talvez a destruição da arquitetura seja a diferença fundamental entre Rem Koolhaas e Peter Eisenman. Eisenman quer a continuidade pela descontinuidade, trazendo muitas vezes conceitos, termos, debates pertencentes a discursos externos no intuito de provocar a 
desnaturalização de entendimentos no discurso da arquitetura. A "arquitetura conceitual" é produzida no discurso da arquitetura, ela age na disciplina, pensa e incentiva seus contratempos, discute sua interioridade (2007, p. 91); Koolhaas quer o externo que atualiza e interfere no discurso, podendo destruí-lo, produzindo outra coisa que não se sabe ao certo o que é. Nesse posicionamento, Eisenman seria um conservador: ele quer que sua disciplina persista: ele trabalha num "espaço fechado" (DELEUZE, 2010, p. 223), tentando modificar seus termos, condutas, condições impostas pelo discurso dominante.

O que se aponta como conservador, entretanto, é um posicionamento sobre a conservação da instituição, num movimento político que se assemelha aquele realizado por grupos que lutam pelo casamento igualitário. Manter o casamento, a instituição, mas ampliar suas possibilidades de relacionamento: pensar e viabilizar a existência de outros amores que fogem da normatividade e que podem surgir; permitir o casamento entre eles é viabilizar legalmente a produção de outras famílias. Koolhaas, por sua vez, coloca-se mais como um observador muitas vezes irônico: ele traz o que é externo não apenas para periclitar o lugar "privilegiado" de uns, o lugar de formação de onde se fala e de onde é permitido falar, mas para apontar uma alegre possibilidade de fim que se faz até mesmo devastadora.

Koolhaas olha atento e irônico, mas não contra-ataca cheio de vigor e de energia; seu movimento é outro que não o da guerra, o da raiva ou de um desejo incontrolável. Sua conquista é delicada e tem força, pois é proveniente de sua sutileza, de sua insistência pela passividade de um observador: um movimento que não é do confronto enraivecido, da vingança, da tragédia e da artilharia pesada.

Minha apresentação esta noite será um pouco mais pessoal. Basicamente, eu acredito poder fazer arquitetura como um jornalista, e uma das coisas mais interessantes sobre o jornalismo é que ele é uma profissão sem a disciplina. Jornalismo é somente um regime de curiosidades, aplicável a qualquer matéria, e eu diria que esse ainda é um fator importante no andar da minha arquitetura. (KOOLHAAS, 2010, p. 11)

Rem Koolhaas não se interessa em praticar um crítico, bom e positivo discurso da arquitetura se concentrando na disciplina da arquitetura; ele quer um "saber alegre" - uma "fröhliche Wissenschaft", referenciando Friedrich Nietzsche (1995, p. 971) - em sua negatividade e em melancolia, flertando com o suicídio, com a depressão e com o luto de um arquiteto que 
prefere se dizer jornalista ao ministrar uma palestra no mesmo Architectural Association (AA) em Londres. Koolhaas é um observador delicado. A alegria se dá na destruição de valores que limitam e que restringem, na exposição de certas ordens, na ruptura com uma disciplina que o conforma.

O Muro de Berlim coloca em evidência a arquitetura e o poder; arquitetura que atende aos poderes, que existe para atendê-los. Arquitetura que perde a boa justificativa da escala humana. A arquitetura apontada pelo muro atende uma necessidade de poder que controla os habitantes da cidade: que os condiciona numa repressão.

Tão capitalista quanto socialista, o muro serve diretamente aos dois regimes. Entretanto, é mais difícil falar sobre a utilização do muro pelo regime capitalista, pois a suposta liberdade que salva ou redime a Berlim ocidental esclarece, pacifica as discussões ao se valer da ameaça que é o socialismo.

A Berlim dividida retoma a "cidade pestilenta" ao mesmo tempo em que se vale do "esquema panóptico" (1997, p. 196) - ou "panoptismo" -, ambos presentes em "Vigiar e punir" de Michel Foucault.

Se a "cidade pestilenta" pode se aproximar daquilo que é chamado de dispositivo, o "esquema panóptico" - ou somente o "panoptismo" -, pode se aproximar do diagrama.

Esse espaço fechado, recortado, vigiado em todos os seus pontos, onde os indivíduos inseridos num lugar fixo, onde os menores movimentos são controlados, onde todos os acontecimentos são registrados, onde um trabalho ininterrupto de escrita liga o centro e a periferia, onde o poder é exercido sem divisão, segundo uma figura hierárquica contínua, onde cada indivíduo é constantemente localizado, examinado e distribuído entre os vivos, os doentes e os mortos - isso tudo constitui um modelo compacto do dispositivo disciplinar. A ordem responde à peste; ela tem como função desfazer todas as confusões: a doença que se transmite quando os corpos se misturam; a do mal que se multiplica quando o medo e a morte desfazem as proibições. Ela prescreve a cada um seu lugar, a cada um seu corpo, a cada um sua doença e sua morte, a cada um seu bem, por meio de um poder onipresente e onisciente que se subdivide ele mesmo de maneira regular e ininterrupta até a determinação final do indivíduo, do que o caracteriza, do que Ihe pertence, o do que Ihe acontece. Contra a peste, que é mistura, a disciplina faz valer seu poder que é análise. (FOUCAULT, 1997, p. 188) 
Num primeiro momento, pensar o "panóptico" como diagrama é estranho: mas aí está a confusão mental realizada por Foucault. A importância dessa confusão é que, a partir dela, surge um entendimento do que pode ser o diagrama e a diferença entre ele e o dispositivo. Dispositivo e diagrama são, ambos, conceitos; e o que ajuda na abordagem das diferenças entre eles é a materialidade e a violência.

"Panóptico" é um conceito; ele não existe materialmente, ele não vem de uma experiência física material; ele também não é apenas uma utopia. O conceito "panóptico," ou o "panoptismo", é trazido para agir no pensamento, na teoria que age nesse próprio "panóptico" da disciplina. Ao trazer o "panóptico" como um diagrama, Foucault identifica a organização do poder, as relações do poder, ordenações que existem. O "panóptico" é uma configuração das relações de força, do poder. Da linguagem - e da utilização da linguagem. Ele é uma metáfora, uma alegoria, talvez; ele é uma representação desconcertante do diagrama.

É pela e na representação que o conceito age. Se faltava a imagem regente por "detrás" do muro, agora pensamos na imagem do "panóptico" por toda Berlim dividida, numa organização que rege amplamente as cidades de maneira silenciosa e que se expressa de diversas maneiras. O muro é um grito de ordem nesse silêncio que delata o esquema do qual faz parte, pelo qual é utilizado, do qual é instrumento.

Mas o panóptico não deve ser compreendido como um edifício onírico: é o diagrama de um mecanismo de poder levado à sua forma ideal: seu funcionamento, abstraindo-se de qualquer obstáculo, resistência ou desgaste, pode ser bem representado como um puro sistema arquitetural e óptico: é na realidade uma figura de tecnologia política que se pode e se deve destacar de qualquer uso específico. É polivalente em suas aplicações: serve para emendar os prisioneiros, mas também para cuidar dos doentes, instruir os escolares, guardar os loucos, fiscalizar os operários, fazer trabalhar os mendigos e ociosos. É um tipo de implantação dos corpos no espaço, de distribuição dos indivíduos em relação mútua, de organização hierárquica, de disposição dos centros e dos canais de poder, de definição de seus instrumentos e de modos de intervenção, que se podem utilizar nos hospitais, nas oficinas, nas escolas, nas prisões. Cada vez que se tratar de uma multiplicidade de indivíduos a que se deve impor uma tarefa ou um comportamento, o esquema panóptico poderá ser utilizado. (FOUCAULT, 1997, p. 194-195) 
A "arquitetura conceitual" de Peter Eisenman trabalha no panóptico, no diagrama. "Ele existe como o espaço potencial da escrita" (2007, p. 93). Já Rem Koolhaas, diferentemente, trabalha com o dispositivo, ou com os dispositivos que existem no mundo. O que diferencia os dois está na apresentação das relações do poder. Falo de alguma visualidade. Eisenman, em sua "arquitetura conceitual," promove o debate do discurso. Koolhaas, em seus diagramas analíticos, mostra funcionamentos e distribuições (a partir) de seus objetos de estudo.

\begin{abstract}
Quando Foucault define o Panoptismo, ora ele o determina concretamente, como um agenciamento óptico ou luminoso que caracteriza a prisão, ora abstratamente, como uma máquina que não apenas se aplica a uma matéria visível em geral (oficina, quartel, escola, hospital, tanto quanto a prisão), mas atravessa geralmente todas as funções enunciáveis. A fórmula abstrata do Panoptismo não é mais, então, "ver sem ser visto", mas impor uma conduta qualquer a uma multiplicidade humana qualquer. Especifica-se apenas que a multiplicidade considerada deve ser reduzida, tomada num espaço restrito, e que a imposição de uma conduta se faz através da repartição no espaço-tempo. (DELEUZE, 2013, p. 43)
\end{abstract}

A "cidade pestilenta" não é um dispositivo único: ela compreende vários dispositivos. Ela pode, como o "panoptismo", também ser pensada enquanto um esquema, enquanto uma organização do poder - e, assim, ser entendida de maneira diagramática. Todavia, a necessidade de diferenciá-la do "panóptico" - e por isso aproximá-la do dispositivo - se deve à maneira explícita pela qual ela opera. O poder, as funções e seus mecanismos estão lá expostos. É o mecanismo, a matéria exposta do Muro que o aproxima dessa configuração que é a "cidade pestilenta". Por sua vez, a Berlim dividida em seu todo - e, sobretudo, a Berlim ocidental capitalista - aproxima-se do que é pensado no "panoptismo".

O esquema panóptico, sem se desfazer nem perder nenhuma de suas propriedades, é destinado a se difundir no corpo social; tem por vocação tornar aí uma função generalizada. A cidade pestilenta dava um modelo disciplinar excepcional: perfeito, mas absolutamente violento; à doença que trazia a morte, o poder opunha sua perpétua ameaça de morte; a vida nela se reduzia a sua expressão mais simples; era contra o poder da morte o exercício minucioso do direito de gládio. O Panóptico, ao contrário, tem um papel de amplificação; organiza-se o poder, não é pelo próprio poder, nem pela salvação imediata de uma sociedade ameaçada: o que importa é tornar mais fortes as forças sociais - aumentar a produção, desenvolver a economia, espalhar a instrução, elevar o nível da moral pública; fazer crescer e multiplicar. (FOUCAULT, 1997, p. 196-197) 
O capitalismo precisa do outro do socialismo para sobreviver e se expandir: precisa do muro. A ameaça de um pelo outro justifica o Muro e as ações. Para além das justificativas, há uma relação de poder que não é concreta, um diagrama de forças que, em silêncio, existe e atua por instrumentos na cidade, no humano que a habita. O diagrama de forças quer a Berlim dividida para, dela, encontrar outros espaços: conhecendo outros instrumentos, elaborando tecnologias materiais que ele domine para dominar.

Se as forças do socialismo constroem o muro num "desespero" - para evitar que os habitantes de Berlim oriental fujam da cidade, pois o regime se vê diante da ameaça de ser preterido -, as forças do capitalismo se valem do muro e da divisão para se amplificarem. O que é importante destacar é que o muro é um trabalho dessas forças, da tensão entre elas - e não somente um movimento único. O diagrama está aí. O "panoptismo" dá uma configuração a ele.

Quando Gordon Matta-Clark é convidado para realizar uma performance na Berlim ocidental em 1976, ele decide colar cartazes e fazer imagens em estêncil no muro. Um vídeo é feito junto da performance - vídeo que não é apenas um documento; vídeo que também é trabalho. É preciso sublinhar quatro ações dessa performance-vídeo.

Gordon Matta-Clark cola cartazes com anúncio de produtos no muro.

Gordon Matta-Clark faz um estêncil em que a bandeira americana e a bandeira soviética são uma só: é uma bandeira misturada, com elementos das duas.

São filmadas as plataformas em que os que passam próximos ao muro, no lado ocidental, podem subir para olhar o lado oriental.

São filmados coelhos que ocupam o espaço entre o muro, numa área baldia entre os lados ocidental e oriental.

A primeira, a segunda e a terceira ação quase explicam e ilustram os fragmentos deste texto. Os coelhos, no entanto, trazem certa alegria para mim enquanto leitor. Eles apontam uma transgressão: viver no espaço entre, naquilo que eu, ingenuamente, tento acreditar ser um espaço distraído do diagrama.

Entre a Berlim ocidental e a Berlim oriental há um "parque" só acessível ao "lazer" desses animais. Investigar o diagrama é, talvez, buscar essas alegrias. Alegrias que desarticulam 
vigilâncias, controles, ordenações. São os coelhos, não os homens que brincam naquele parque. Jean Baudrillard chamará o espaço entre os muros de "no-man's land" (apud KOOLHAAS, 1995, p.1282) e os coelhos de "sinais engraçados" (apud KOOLHAAS, 1995, p.1282).

E por que pensar nos coelhos para pensar o "diagrama" e o "dispositivo" ? Eles talvez comprovem o envolvimento da "tecnologia humana" e da "tecnologia material". Eles não são afetados pelas relações de força que proporcionam a construção do muro. No parque do "no-man's land", eles brincam - digo brincam na tentativa de causar um contraste diante da dureza do muro, do limite.

Artigo recebido em julho de 2016 e aprovado em agosto de 2016.

\section{Referências}

2001: UMA ODISSÉIA NO ESPAÇO. Stanley Kubrick, 1969.

AGAMBEN, Giorgio. O homem sem conteúdo. Belo Horizonte: Autêntica Editora, 2013.

Alien, o oitavo passageiro. Ridley Scott, 1979.

BARTHES, Roland. A câmara clara. Rio de Janeiro: Nova Fronteira, 1984.

BENJAMIN, Walter. A origem do drama trágico alemão. Belo Horizonte: Autêntica Editora, 2013.

BENJAMIN, Walter. Obras escolhidas: Mágia e técnica, arte e política. São Paulo: Brasiliense, 1994.

BLADE RUNNER. Ridley Scott, 1982.

BRANCO SAI, PRETO FICA. Adirley Queirós, 2015.

BRUM, Eliane. "Os Silva são diferentes". El país. 2014. Disponível em: http://brasil.elpais.com/brasil/2014/09/01/opinion/1409578464_024733.htmlAcessado em: 20/05/2015

Caché. Michel Haneke, 2005

DELEUZE, Gilles. Conversações. São Paulo: Editora 34, 2010.

DELEUZE, Gilles. Crítica e clínica. São Paulo: Editora 34, 2011.

DELEUZE, Gilles. Foucault. São Paulo: Brasiliense. 2013.

DELEUZE, Gilles; GUATTARI, Félix. Mil platôs: capitalismo e esquizofrenia 2, vol. 4. São Paulo: Editora $34,2012$.

DERRIDA, Jacques. "An exchange between Jacques Derrida and Peter Eisenman". In: Assemblage, v. 12. Cambrige: The MIT Press, 
1990. Disponível em: http://roundtable.kein.org/node/611 Acessado em: 20/05/2015

EISENMAN, Peter. "Arquitetura e o problema da figura retórica."In: NESBITT, K. (Org.). Uma nova agenda para a arquitetura: antologia teórica. São Paulo: Cosac Naify, 2008.

EISENMAN, Peter. "Notes on conceptual architecture: Toward a definition". In: Inside Out: Selected Writings, 1963-1988. New Haven: Yale University Press, 2004

EISENMAN, Peter. "Visões que se desdobram."In: NESBITT, K. (Org.). Uma nova agenda para a arquitetura: antologia teórica. São Paulo: Cosac Naify, 2008

EISENMAN, Peter; KOOLHAAS, Rem. Supercritical. Londres: AA Publications, 2010

EISENMAN, Peter. "Peter Eisenman about the Memorial". In: The Memorial of Murdered Jews in Europe. Background Information. Página da internet. Disponível em: http://www.stiftung-denkmal.de/en/memorials/the-memorial-to-the-murdered-jews-of-europe/peter-eisenman.html. Acessado em: 25/06/2015

EISENMAN, Peter. Written into the void. New Haven e Londres: Yale University Perss, 2007

FOUCAULT, Michel. Ditos e escritos III: Estética: literatura e pintura, música e cinema. Rio de Janeiro: Forense, 2001.

FOUCAULT, Michel. A ordem do discurso. São Paulo: Edições Loyola, 2013.

FOUCAULT, Michel. Vigiar e punir: nascimento da prisão. Petrópolis: Vozes, 2013.

FRIED, Michael. "Arte e objetidade". In: Revista arte e ensaios, n.9, 2002. Disponível em: ppgav.eba.ufrj.br/producao/arte-ensaios.9 Acessado em: 15/04/15

HITCHCOCK, Alfred; TRUFFAUT, François. Dialogue between Truffaut and Hitchcock. Nova York: Touchstone, 1985.

HEIDEGGER, Martin. “Construir, habitar, pensar". In: Ensaios e conferências. Petrópolis: Vozes, 2012.

Histoire(s) du cinéma, Jean-Luc Godard, 1998.

KOOLHAAS, Rem. S, M, L, XL. Nova York: The Monacelli Press, 1995.

MORRIS, Robert. "O tempo presente do espaço". In: COTRIM, Cecília; FERREIRA, Glória (Org.). Escritos de artistas: anos 60/70. Rio de Janeiro: Zahar, 2006.

MORRISON, Toni. Nobel Lecture, 7 de Dezembro, 1993. Academia sueca. http://www.nobelprize.org/nobel_prizes/literature/laureates/1993/morrison-lecture.html Acesso: 29/09/14

OWENS, Craig. "Earthwords." In: October, vol. 10, 1979. Disponível em: http://www.jstor.org/stable/778632?\&seq=2\#page_scan_tab_ contents Acessado em: 23/06/2015

PIGNATARI, Décio. Interessere. 1974. Disponível na página da web: http://www.fundacaobienal.art.br/7bienalmercosul/en/decio-pignatari Acesso: 22/11/2013

O SACRIFíCIO. Andrei Tarkovsky, 1986. 
SPIRAL JETTY. Robert Smithson, 1970.

STENGER, Isabelle. "Gaia, the Urgency to Think (and Feel)". Palestra no colóqui Os mil nomes de gaia: do Antropoceno à Idade da Terra. Fundação Casa de Rui Barbosa, 2014. Disponível em: https://osmilnomesdegaia.files.wordpress.com/2014/11/isabelle-stengers. pdf Acessado em: 20/05/2015

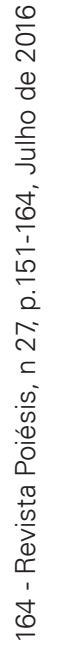

VIRGEM. Antonio Cícero; Marina Lima, 1987.

WAGNER, Anne. "Reading Minimalism". In: BATTCOCK, Gregory (Org.). Minimal art: A Critical Anthology. Berkley e Los Angeles: University of California Press, 1995.

THE ARTIST IS PRESENT. Marina Abramovich, 2009

THE WALL. Gordon Matta-Clark, 1976. 